\title{
Research on Integrated Design of Modular Steel Structure Container Buildings Based on BIM
}

\author{
Meng Su $\left(D,{ }^{1}\right.$ Bauer Yang $\mathbb{D}^{2},{ }^{2}$ and Xiaomin Wang $\mathbb{D}^{3}$ \\ ${ }^{1}$ School of Architectural Science and Engineering, Yangzhou University, Yangzhou 225127, China \\ ${ }^{2}$ Yangzhou Tonglee Reefer Container Co, Ltd., Yangzhou 225102, China \\ ${ }^{3}$ Jiangsu Provincial Architectural D\&R Institute Co, Ltd., Nanjing 210019, China
}

Correspondence should be addressed to Meng Su; 834157071@qq.com

Received 19 October 2021; Accepted 13 December 2021; Published 17 January 2022

Academic Editor: Qian Chen

Copyright $\odot 2022$ Meng Su et al. This is an open access article distributed under the Creative Commons Attribution License, which permits unrestricted use, distribution, and reproduction in any medium, provided the original work is properly cited.

\begin{abstract}
Modular container buildings, as new modular steel structure buildings with the advantages of modular construction and transportation, fast construction speed, and conformance to the concept of sustainable development, have achieved rapid development in the field of civil engineering in recent years. However, in view of the incompatibility of the standards and systems between the traditional construction industry and the container manufacturing industry, contradictions between industrialization, standardization requirements and diversified demands of buildings, and the low integration of the design system of modular steel structure buildings, the further development of the modular container building industry has encountered a bottleneck. In this study, for resolving this problem, it was proposed to coordinate the modular sequence of the construction and container manufacturing, establish a modular system for modular steel structure buildings, establish a database of container building components and parts, and integrate BIM and PDM platforms, to strengthen professional coordination and improve the integrated design that can increase the integration of the whole process of design. The application and verification in pilot projects such as Huaduhui Commercial Street have approved that this design method can effectively improve the standardization, industrialization, and information levels of design, production, and construction, increase the diversity and overall quality of modular buildings, and promote the achievement of the integration target of the modular steel structure building system.
\end{abstract}

\section{Introduction}

Modular container buildings, as new modular steel structure buildings, have not been applied in civil engineering for a long time, and they have been used to civil buildings on a large scale for only more than ten years. At the end of the twentieth century, many Western architects started designing container buildings, most of which were the transformation of small modular buildings focusing on experimental trials [1]. In the twenty-first century, the new building type, "modular steel structure container building," entered a period of development in the field of civil engineering and formed a unique architectural style and construction method [2,3]. Since then, modular container buildings have been gradually applied as residences, stores, offices, hotels, etc. [4]. In 2019, for fighting against COVID-19, Huoshenshan and Leishenshan hospitals were rapidly constructed, showing the unique advantages and development potential of modular steel structure container buildings [5].

In the past two decades, some companies and engineers have studied modular steel structure container buildings' design and manufacture and made many achievements (Table 1). For example, SG Blocks (the USA) and Tempohousing (Netherlands) are good at building large-scale residential buildings such as barracks and dormitories; Urban Space Management (UK) and LOT-EK (the USA) have designed diversified and characteristic container buildings such as schools, offices, and business buildings [6]; Verbus Systems (UK) has obtained a patent for vertically stacked container buildings [7]; Shigeru Ban, the winner of the Pulitzer Prize, has successfully applied used containers in architectural design of the buildings such as the nomadic museum [8]. In recent years, 
TABLE 1: Famous container design and manufacturing company and its works.

\begin{tabular}{|c|c|c|c|}
\hline Company & Country & Representative projects & Awards or achievements \\
\hline $\begin{array}{l}\text { LOT-EK } \\
\text { SG Blocks }\end{array}$ & America & $\begin{array}{l}\text { Puma City } \\
\text { Container City } 2008 \\
\text { Apap Open School } \\
\text { The CUBES at Socrates Sculpture Park } \\
\text { U.S. Army Corps of Engineers Barracks }\end{array}$ & $\begin{array}{c}\text { American National Design Award (2008) } \\
\text { AIA Award (2011) } \\
\text { PDC Annual Award (2018) }\end{array}$ \\
\hline $\begin{array}{l}\text { Verbus Systems } \\
\text { Urban Space Management }\end{array}$ & UK & $\begin{array}{c}\text { Travelodge Hotel } \\
\text { Container City1, } 2 \\
\text { Cuffley School } \\
\text { Fawood Children's Center }\end{array}$ & $\begin{array}{l}\text { The Container City System } \\
\text { RIBA Stirling Prize (2009) }\end{array}$ \\
\hline Tempohousing & Holland & Keetwonen Student Housing & \\
\hline Addis Containers & New Zealand & Container RowBox & 2010 Karapiro World Rowing Champs Promotional \\
\hline CIMC & China & $\begin{array}{l}\text { Sochi Winter Olympics Hotel } \\
\text { Holiday Inn Express Hotel }\end{array}$ & \\
\hline
\end{tabular}

Jure Kotnik prepared the book Container Architecture, which introduces representative container buildings and theoretical research results. In Prefab Architecture: A Guide to Modular Design and Construction, the author conducts more in-depth analysis on the key points of the whole process, from components, panels, assembly to design and construction of the prefabricated container buildings. Eissa et al. investigate the development of a BIM governance framework (G-BIM) with the support of cloud technologies, identifying effectiveness factors that guarantee successful collaboration [9]. Ansah et al. extend the knowledge in automated BIM-based LCA by addressing specific characteristics of prefabrication and promotes the incorporation of comprehensive and detailed LCA data into BIM models for improved design robustness and holistic performances of buildings [10]. China International Marine Containers (Group) Co., Ltd., as the largest container manufacturer in the world, has made various achievements in the field of modular steel structure buildings. For example, it has developed the "seismic model analysis of modular building with self-stacking structure" technology with domestic universities [11]. The pioneered modular building technology has been applied in hotels for the Russian Winter Olympics.

However, there is a dilemma in the development of modular steel structure buildings at present: on the one hand, the industrialized mass production of modular steel structure buildings mainly depends on container manufacturers, and the facilities are primarily limited to low-end dormitories and stores consisting of a large number of repeated and straightforward units; on the other hand, as for modular steel structure buildings with higher quality requirements, although there are construction companies involved in the design and construction, the inconsistency of the standards with the container enterprises, the low system integration, and unfavorable transdisciplinary coordination have resulted in several problems such as common design integration, redundant types of modules and components, low production efficiency, and high cost, which have severely restricted the development of the industry of container buildings.

For resolving such a problem, in this paper, the author coordinated the related modulus and size restrictions in the traditional construction industry, container manufacturing industry, and logistics industry based on the BIM platform and pilot projects and the advantages of BIM informatization, and then proposed a unified modular sequence and three-dimensional modular grid for modular container buildings. In addition, the author established a standardized and systematic database of components and parts characterized by "family" through the integration of building information modeling (BIM) and product data management (PDM) platforms and an integrated design method of container buildings led by architectural design based on a flexible modular combination and closely cooperated with structure and equipment, for realizing the standardization and digitization of the whole process of design, production, and construction. The completion and operation of the pilot projects such as Huaduhui Commercial Street (Figure 1) and Modular Fire Station have verified the feasibility and superiority of the integrated design of modular container buildings based on BIM.

The paper is organized as follows. Section 2 discusses the link between the goal of modular container building integration and BIM-based integrated design; Section 3 discusses a modular container building system based on BIM technology and components from the container logistics and conventional construction industries; Section 4 describes BIM database for modules, features, and parts of modular steel structure buildings; Section 5 describes integrated design and pilot projects for container buildings based on BIM and crossdisciplinary collaboration in design, production, and construction; and Section 6 provides conclusion.

\section{Integration Target of Modular Steel Structure Container Buildings and Integrated Design Based on BIM}

For resolving the contradiction between the diversified needs of modular container buildings and industrial production, there should be an integrated building system combining standardization with flexibility similar to KEP (Kodan Experimental Housing Project) and NPS (new plain system) in Japan [12]. Integrated buildings are assembled by building components in a manner of plant and social collaboration, which form a new building system that can 


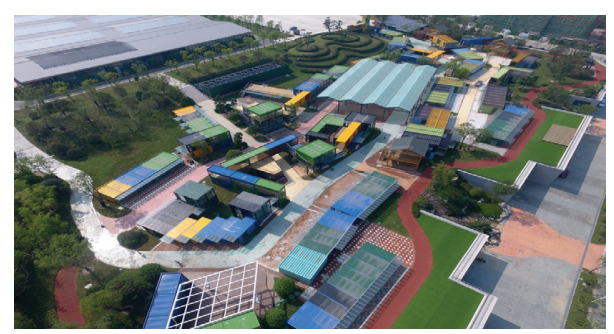

Figure 1: Pilot project-real aerial photo of Huaduhui Commercial Street.

provide ultimate perfect products for the market. The integrated building system can integrate building components and structural parts and provide optimized products that combine integration design, information-based production management methods, and high-performance materials and equipment. In order to establish the integration building system, Yangzhou University and CIMC Yangzhou Base jointly proposed the integration target for the container building system (Table 2).

Integrated design is the prerequisite and means for achieving the container building integration target. A multidisciplinary design method can be used to construct economic and high-quality facilities. A multidisciplinary design method can be used to construct economic and highquality buildings by integrating various design elements in the design process. From a vertical perspective, integrated design runs through and leads the entire design, construction, and operation process and focuses on the whole life cycle of the building. From a horizontal perspective, different professional designers should work closely together and consider the form, function, performance, and cost to obtain high performance and various benefits at a lower price, thus realizing the sustainable development of the building. [13] BIM is the basis for the goal of integrated design. To realize the integration of different professional software and the mutual access between databases, all the professional data, system software, and application software must adopt the uniform model data expression and information exchange standards in the BIM system [14].

\section{Establishment of a Modulus System for Modular Container Building Based on BIM}

Integrated design should coordinate the size, positioning, and correlation of the main structure, components, and parts, and establish a unified and coordinated modular grid system through modular and serial design to realize the organic combination between structure, features, and equipment, and simplify the size and types of components. In other words, a modulus system is a prerequisite and foundation for establishing an integrated design system for container buildings. BIM technology has provided a platform for the establishment of such a system.

3.1. Modulus Coordination. For establishing a modulus system of modular container buildings, the building modulus system and container logistics modulus system in the traditional construction industry should be first integrated. Specifically, in addition to the modulus based on the human scale, the modulus based on functional units, and building modules based on the size of the building components that should be integrated in the general building modulus system, the logistics modules, transportation size restrictions, container structural components, and material size modulus should also be deeply analyzed, so as to obtain the differences and mutual relations between different modulus systems. Then, the major constraint modulus and dimensions can be proposed on this basis to integrate and form a new container building modulus system (Figure 2).

Particular attention should be attached to the limitations on transportation dimensions because an essential feature of container buildings is the overall transportation of modules. It can be concluded through analyzing the Regulations on Transport Vehicles with Out-of-Gauge Goods and Limits of Outer Dimensions, Axle Loads and Mass of Automobiles, Trailers and Combination Vehicles (GB1589-2016) that there are limitations on transportation of large-size goods $(2.5 \mathrm{M}, 3 \mathrm{M}, 3.75 \mathrm{M}$, etc.) and also on height and length. Therefore, in the process of modulus coordination, the hierarchical modulus on width, height, and length of the module should be smaller than these values, respectively. The complexity of modulus may significantly increase the possibility of size combination. Since the cad plane, facade, and section cannot coordinate and control the varieties of modulus and modules in a 3D space, BIM was used to build a 3D model for simulated combination testing of modulus and modules. The method is first of all, find typical office, hotel, and residential architectural drawings, and use modules of different modulus sizes to puzzle in Revit. It must be ensured that (1) the outline of the module does not exceed the exterior wall of the building; (2) the module does not invade the stairwell; (3) no corner posts appear in the aisle; and (4) the size of the module meets the requirements of transportation and components; and secondly, when the module has basically completed the construction and modeling of the shape and space, use the collision check function of the Revit software to check. When the type is reduced, the building module often collides; then, by comparing the number of collisions in the collision check report with Revit, the ratio of the module types counted in the software, the modules with a lower ratio are selected; finally, there are correct validation and optimization of results. In the Revit system, the parameter adjustment and statistics of building components and parts are very convenient, which greatly improves the research efficiency. Thereby, the results of the 
TABLe 2: Container modular building system integration target list.

\begin{tabular}{|c|c|c|}
\hline Target & Rule & Index \\
\hline \multirow{3}{*}{ Integration of architectural design } & Modular system & $\begin{array}{c}\text { Realize modular coordination, establish modular mesh, tolerance, } \\
\text { and fit, connection, etc. }\end{array}$ \\
\hline & General module, component & $\begin{array}{l}\text { A large proportion of modules, prefabricated components, or } \\
\text { components of the exact design specification }\end{array}$ \\
\hline & Professional cooperation & $\begin{array}{l}\text { BIM as a platform to achieve the architecture, structure, } \\
\text { hydropower, HVAC professional close cooperation }\end{array}$ \\
\hline \multirow{4}{*}{$\begin{array}{l}\text { Component parts production } \\
\text { standardization, factory production }\end{array}$} & $\begin{array}{l}\text { Prefabricated load-bearing } \\
\text { member }\end{array}$ & Modules, columns, beams, floors \\
\hline & $\begin{array}{l}\text { Prefabricated non-load- } \\
\text { bearing component }\end{array}$ & $\begin{array}{c}\text { Interior wall, balcony, staircase, integral kitchen, integral } \\
\text { bathroom, etc. }\end{array}$ \\
\hline & $\begin{array}{l}\text { Prefabrication rate of load- } \\
\text { bearing components }\end{array}$ & Improve prefabricated volume ratio or prefabricated value ratio \\
\hline & $\begin{array}{l}\text { Prefabrication rate of non- } \\
\text { load-bearing components }\end{array}$ & Improve prefabricated volume ratio or prefabricated value ratio \\
\hline \multirow{4}{*}{ Assembly of building construction } & $\begin{array}{l}\text { Mode of transportation of } \\
\text { components and parts }\end{array}$ & $\begin{array}{l}\text { Prefabricated components and prefabricated parts shall be given } \\
\text { priority to the size following transportation regulations, the } \\
\text { integrated transportation mode shall be given priority, and the } \\
\text { multimodal transportation mode shall be adopted for long- } \\
\text { distance transportation. }\end{array}$ \\
\hline & Technical equipment rate & $\begin{array}{l}\text { Increase the ratio of the net value of enterprise-owned machinery } \\
\text { and equipment to the total number of employees or workers at the } \\
\text { end of the year }\end{array}$ \\
\hline & Power equipment ratio & $\begin{array}{c}\text { Increase the ratio of the total power of machinery and equipment } \\
\text { to the average number of employees }\end{array}$ \\
\hline & $\begin{array}{l}\text { Degree of technology } \\
\text { integration }\end{array}$ & $\begin{array}{l}\text { Improve the degree of technical integration, upgrade the } \\
\text { secondary design, complete set of the installation process }\end{array}$ \\
\hline \multirow{5}{*}{$\begin{array}{l}\text { Production and management } \\
\text { informatization }\end{array}$} & The phase of the design & $\begin{array}{c}\text { Application of information technology (BIM, the Internet of } \\
\text { Things, etc.) }\end{array}$ \\
\hline & $\begin{array}{c}\text { Component parts production } \\
\text { stage }\end{array}$ & $\begin{array}{c}\text { Application of information technology (BIM, the Internet of } \\
\text { Things, etc.) }\end{array}$ \\
\hline & $\begin{array}{c}\text { Construction and installation } \\
\text { stage }\end{array}$ & $\begin{array}{c}\text { Application of information technology (BIM, the Internet of } \\
\text { Things, etc.) }\end{array}$ \\
\hline & Operational phase & $\begin{array}{c}\text { Application of information technology (BIM, the Internet of } \\
\text { Things, etc.) }\end{array}$ \\
\hline & $\begin{array}{l}\text { Life cycle information } \\
\text { management }\end{array}$ & $\begin{array}{l}\text { Integrated information technology approaches throughout life } \\
\text { cycle management }\end{array}$ \\
\hline
\end{tabular}

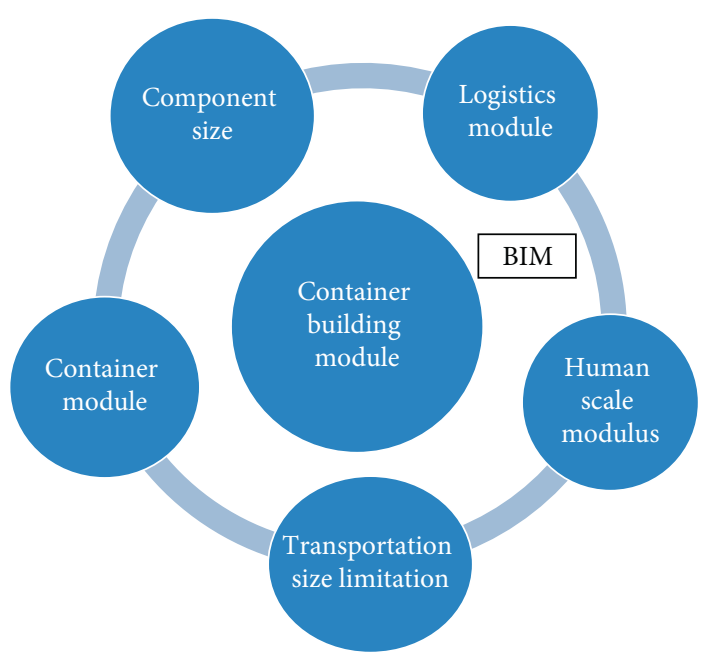

FIgURE 2: Modulus coordination of modular container buildings based on BIM. 
first phase of the study can be verified, screened, and optimized, and the applicable modulus, module, and component size can be obtained.

3.2. Establishment of the Modulus System. Based on BIM simulation, screening, and optimization, the container building modulus system was initially proposed, based on which we designed the components, parts, and modules and then performed the trial installation. Through verification, adjustment, and improvement by several actual projects, the container building modulus system was initially established and included as essential parts into the internal standards of CIMCStandards for Container Modular Combination Barracks and Standards for Self-stacking Container Modular Hotel.

The container modulus system consists of the following parts.

3.2.1. Determination of Modulus Sequence. In order to realize the standardization of the design of container buildings and offer greater versatility and interconvertibility to the structure and components in a facility, the limited sequence should be taken as actual working parameters in architectural design. Firstly, we determined (1) the basic modulus $1 \mathrm{M}$, then determined (2) expanded modulus sequence ( $2 \mathrm{M}$, $4 \mathrm{M}, 6 \mathrm{M})$ based on the principle of superposition and multiple, and set (3) submodulus sequence: $M / 100, M / 50$, $\mathrm{M} / 20, \mathrm{M} / 10, \mathrm{M} / 5, \mathrm{M} / 2$, etc. The main range of expanded modulus and submodulus set here is different from that of ordinary buildings because it is determined by the modular features of prefabricated container buildings and the higher manufacturing and assembly accuracy of the machinery manufacturing industry than the traditional construction industry. Finally, (4) adjusted modulus based on English units was set to resolve the connection and conversion issues between the British and metric systems. Specifically, add an inserted value (insert segment) to the metric-based modulus series and the modulus grid. For example, the width of the international standard container is 8 feet, which is $2438 \mathrm{~mm}$; then based on the metric module grid, add a $38 \mathrm{~mm}$ insert section; $2400 \mathrm{~mm}+38 \mathrm{~mm}=2438 \mathrm{~mm}(8 \mathrm{ft})$, where $38 \mathrm{~mm}$ is the adjustment modulus $\mathrm{M}^{\prime}$. And $38 \mathrm{mmX} 2=76 \mathrm{~mm}$ (3in) $=$ $i$, where $76 \mathrm{~mm}$ happens to be the gap size $i$ of the module splicing in the container module system, and its value is 3 inches, that is to say, the adjustment module $\mathrm{M}^{\prime}=i / 2$. As a result, the international standard container module system based on the British system can be converted to the metric building module.

3.2.2. Establishment of a Modular Grid. For each container building, a modularized spatial grid composed of threedimensional rectangular coordinates (modulus dimensions) should be established in BIM. The relevant modulus and parameters can be intuitively analyzed and adjusted; the expanded modulus and sun modulus are different in three directions. A final 3D modular grid of the container building system was established through optimization.
3.2.3. Principle of Positioning. In the modular grid, each component should be positioned by virtue of the boundary positioning of the centerline (or off-center line) in the three directions. Unlike conventional buildings, container buildings are constructed in a modular construction manner, so they are not applicable to the principle of positioning with the centerline (or off-center line) of column (beam) or wall but the code of placing with seam line as the positioning axis. At each end of the building, the modular grid lines can be set on the boundary surface of the module (Figure 3(a)).

3.2.4. Mark Dimensions, Production Dimensions, Seam, and Tolerance. In order to realize the size coordination between the design and installation of the containerized modular building and open up the data conversion between design and manufacturing, the relationship between the size of the logo and the size of the production needs to be handled. The size of the logo should be the modular size and meet the requirements of the modular sequence, usually indicating the distance between the building positioning lines (axis); the production size is the design size of the building module, parts, and components; the general production size plus the seam size or joint size is mark dimensions. The seam mainly refers to the gap between two or more modules in the container building modulus system. By optimizing the design and improving the production and installation process, the seam width of CIMC containers has been reduced to $10 \mathrm{~mm}$ from the original $20 \mathrm{~mm}$ (or $18 \mathrm{~mm}$ ). Tolerance is the difference between two allowable limits, including manufacturing tolerance, installation tolerance, and positioning tolerance. The tolerance in the container construction system generally refers to the manufacturing tolerance, which is the difference between the production size and the actual part size. Considering the higher accuracy of container buildings compared to traditional buildings, we set the tolerance of container buildings at the millimeter level. For example, the manufacturing tolerances of container modules were controlled within the range of 0 to $-5 \mathrm{~mm}$. The sum of production dimensions, tolerance, and seam should be the marked dimensions, which can avoid recutting or rectifying (Figure $3(\mathrm{~b})$ ).

\subsection{Application and Inspection of Modulus System in Actual} Projects. The modulus system obtained through simulation, screening, and optimization based on the BIM platform should be inspected and improved throughout the entire process of the actual engineering projects. The pilot projects adopting the new modulus system are introduced below.

Huaduhui Tourist Service Center was designed based on the modulus of $3,000 \mathrm{~mm}$ in height, which can achieve higher indoor space while meeting the size permitted for road transportation; the modulus of the width of $2,438 \mathrm{~mm} \times 2 \mathrm{can}$ meet the space requirements. The entire building was constructed by 17 modules of the same size (side panels were removed at the splicing). The size of every single module did not limit the shape and space of the building. The BIM 3D 

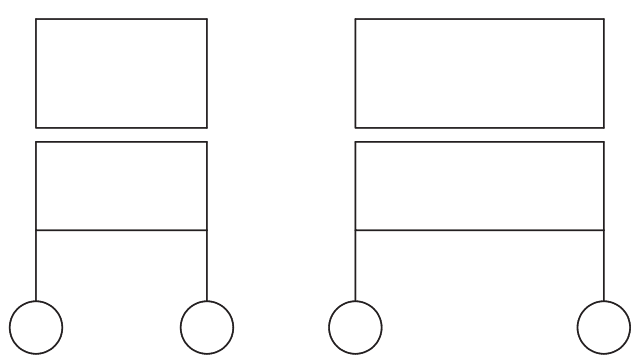

Single container axis position

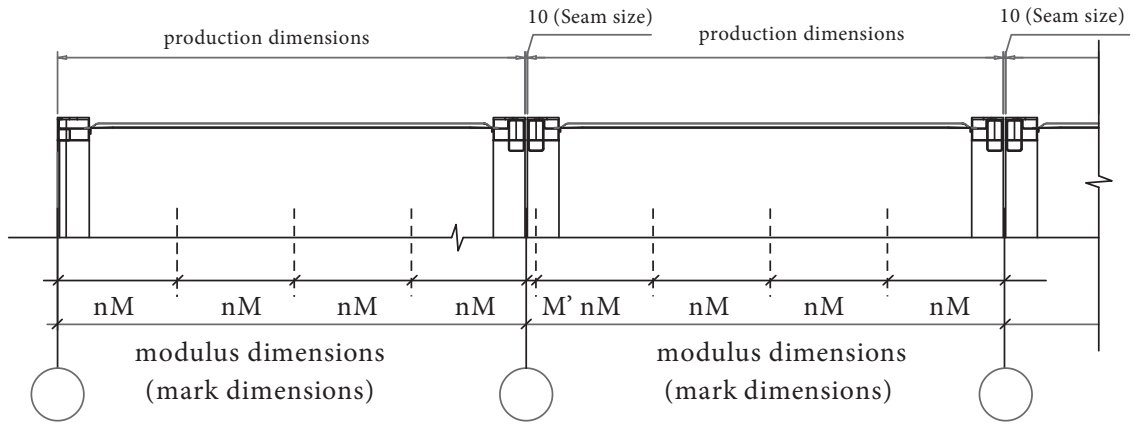

(b)

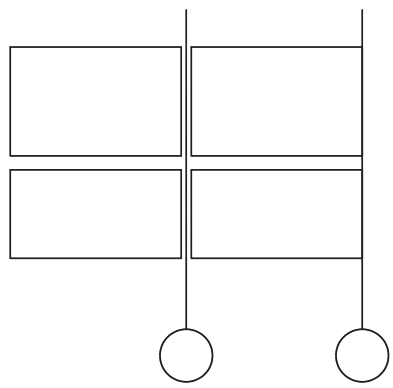

Axis positioning of multiple containers (a)

Figure 3: Principle of positioning. (a) Schematic diagram of axis positioning principles. (b) Schematic diagram of the seam, nominal dimensions, and structural dimensions.

modular grid can easily and intuitively generate different modular combinations in the $3 \mathrm{D}$ space grid. Finally, it forms the well-proportioned building rich in space and conforming to the principle of modularization (Figure 4).

In Huaduhui Commercial Street Project, the container splicing (opening the side walls) was adopted to meet the stores' requirements for space. As for module width, $2,438 \mathrm{~mm}$ was set for a spliced container and 3,000 $\mathrm{mm}$ for an independent container (structural dimension); as for height, 3,200 mm was selected as the significant modulus; as for length, 20, 30, and 40 feet were adopted.

The sizes and styles of components and parts were also simplified, but based on different combinations of interchangeable components and flexible application of orthogonal and oblique 3D modular grids (Figure 5), multiple combinations and spatial effects were obtained with fewer modules and components (Figure 1). The container building modulus system has also been applied in Yangzhou Suburb Park Maker Center, Modular Fire Stations, and other projects, all of which have made satisfactory achievements.

\section{Establishment of a Database of BIM Modules and Components for Modular Steel Structure Container Buildings}

The establishment of the database of BIM modules, components, and parts and the establishment of the modulus system are mutually complementary. In the database, the information such as size and style of modules and features can be integrated; Autodesk Revit software was used to establish a "family" library of various prefabricated components (such as corner fittings, beams and columns, plates, doors, and windows) (Figure 6). In order to ensure quality, improve efficiency, and save cost, we used partial standard parts of container manufacturing enterprises in the architectural design of the projects, such as Huaduhui Tourist Service Center, and firstly established a highprecision standard component model library for coordinating the relevant standards in the construction industry and manufacturing industry based on modulus coordination; we also installed SECR software on the computer for mechanical manufacturing design and that for architectural design equipped with BIM software, and connected them with the server, to realize the compatibility between PDM data and BIM data [15].

Then, a database of nonstandard components and parts was established based on the database of standard features. After continuous accumulation and enrichment of the database, the "families" of the same type were compared to form the normal shape and modular dimensions of prefabricated building components. The modulus system has promoted standardization and serialization of the database, and the "family" library of prefabricated components has effectively promoted the optimization of the modulus system of prefabricated buildings and the establishment of design standards for container building enterprises. While the construction of the component model databased consumes massive time and energy, its establishment would be of great 


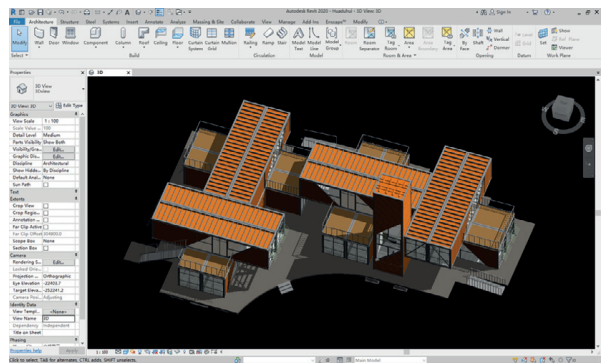

Figure 4: BIM model of the Tourist Service Center based on BIM platform (Autodesk Revit).

convenience for later project design to directly invoke the model from the database.

\section{Design Integration of Modular Container Buildings Based on BIM and PDM}

The establishment of the modulus system has formed a framework. The database has prepared the materials for the modular container building system. In contrast, the platform based on BIM and PDM has integrated data and software of different disciplines in the two industries and throughout the whole process of construction (Figure 7), forming the critical conditions for the design integration of the container building system.

BIM technology has provided strong support for architectural design, calculation analysis, cost management, and construction simulation, which have made it a core platform for information design and management in the construction industry. In contrast, as product data system of the manufacturing industry, PDM has become a core platform for digital design, manufacturing, and management of components and products throughout the life cycle. Therefore, in order to achieve a high degree of integration of container buildings, BIM should be integrated with PDM, and architectural design should be closely connected with factory production of parts and components [16], to realize the digital connection between architectural design and factory manufacturing design, and two-way synchronous design of architectural design and factory manufacturing, thus learning intelligent management and operation and maintenance [17].

BIM platforms can disclose and share design information. During design, the design plan of a container building can be uploaded to the "cloud" server for integrating the information such as dimensions and styles, accumulating and enriching basic modular combinations of prefabricated buildings with various standardized modules and "family" libraries, and saving design and adjustment time, thus increasing the varieties, improving the adaptability of prefabricated buildings, and better meeting the diversified needs. Integrated design based on BIM can better realize information sharing and coordination of various disciplines. For example, in the project of Shuangyu Island Hotel, the design model contained a large amount of design information (geometric information, material performance, and component properties); therefore, through introducing the model into performance analysis software, technical analysis on sunshine and energy consumption can be carried out, which can improve the design plan. In particular, since modular buildings are different from ordinary ones in surface area and shape coefficient [18], the performance analysis can be conducted based on the BIM model in terms of energy conservation and other factors (Figure 8).

The integrated design of modular steel structure buildings should be conducted based on design coordination among different disciplines:

\subsection{Modular Building Design Leading the Overall Direction.} The integrated design of container buildings should be conducted based on coordination of various disciplines and whole process control, while architectural design plays the leading role. The successful container building design depends on the modular and standardized thinking from the phase of setting the architectural plan; the requirements of all disciplines should be comprehensively considered to create high-quality prefabricated buildings with unique shapes and applicable functions.

The pilot project "Modular Fire Station" is a modular firefighting duty building flexibly displayed in a city (Figure 9(a)). With the functions of fire command, fire garage, dormitory, kitchen and bathroom, and leisure, it can be placed in a key firefighting area for rapid response and rescue. This product is designed as a modular building, which can be expanded based on the 3D modular grid and standardized modular design, and the combination mode can also be adjusted, thus adapting to terrains of different sizes and shapes. The standardized and modular design can enable the plant to produce functional modules in batches, which can be assembled according to the actual needs of each project. In this project, a serialization design was performed, which can add or decrease functional modules according to the service radius and basic real needs, to adapt to different sizes of fire stations (one to five firefighting trucks). Such stations have been applied in cities such as Yangzhou, Langfang, and Shenzhen and have been well praised. Other pilot projects, such as "Xiangyu" Residence in Yangzhou Software Park [19] and Yangzhou Suburb Park Maker Center (Figures 9(b) and 9(d)), created functional and diverse architectural spaces and realized the integrated design and industrial production.

5.2. Design and Manufacture of Modular Steel Structure Buildings Based on BIM and PDM Coordination. 


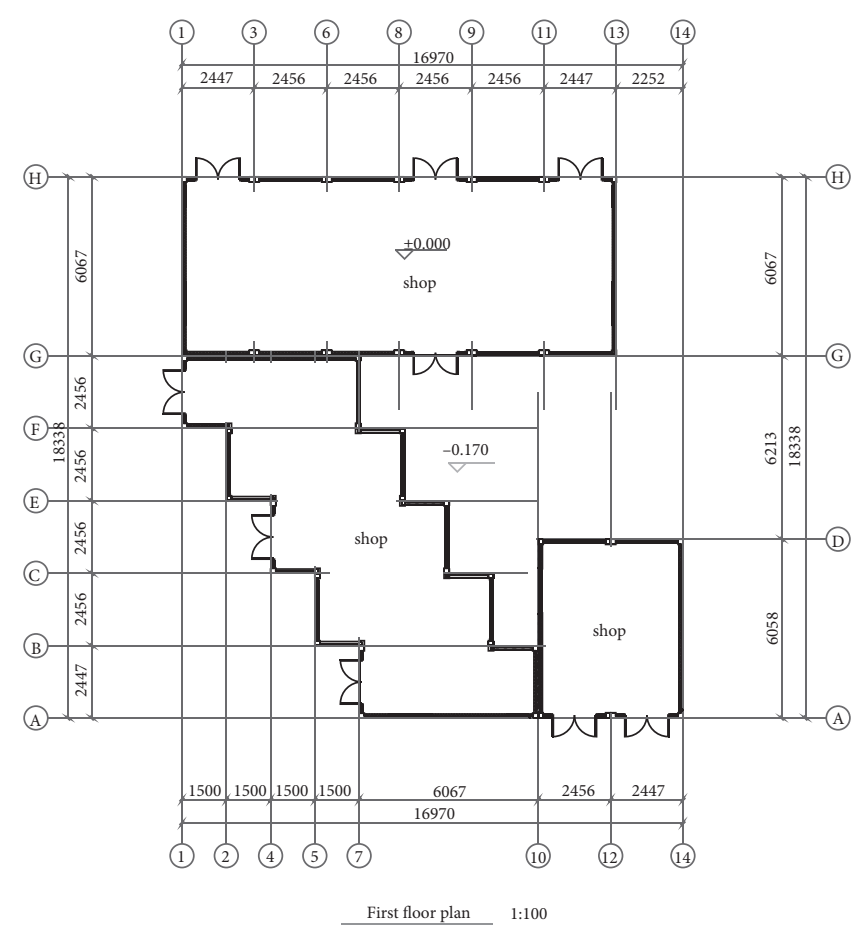

(a)

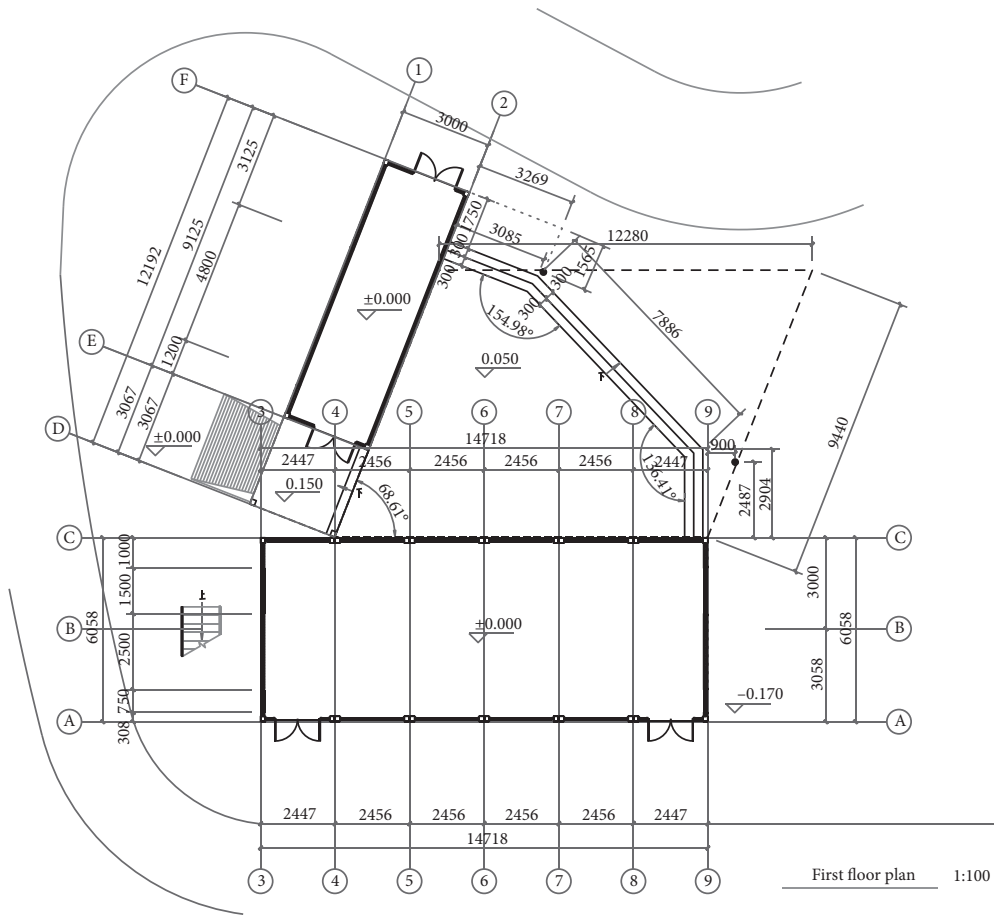

(b)

Figure 5: Modular grid plane (Huaduhui Commercial Street). (a) Orthogonal modular grid plane. (b) Oblique modular grid plane.

Container buildings are assembled in a modularized manner, which is not a conventional structural system, and may bring specific difficulties to the structural design [20]. The platform and structural component database based on BIM and PDM can bring convenience to the finite element analysis of the structure (Figure 10). With the BIM model, we can export IFC file with Revit and then import it into Tongji 3D3S, MIDAS
GEN, and other structural analysis software for finite element analysis so as to evaluate and analyze the seismic performance and stress of the main structure of modular buildings [21]; in addition, PKPM.STS based on building structural calculations and MSC Nastran (the structural CAE simulation analysis and calculation software of mechanical products) can be used for structural calculation on parts and components [22]; if the 


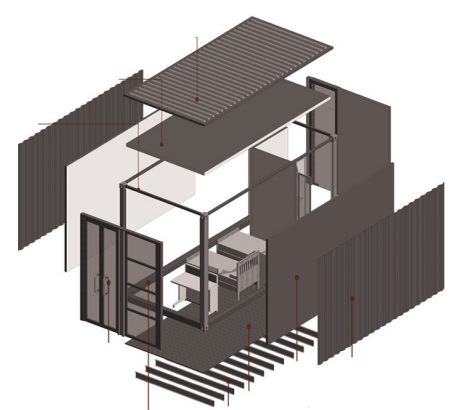

(a)

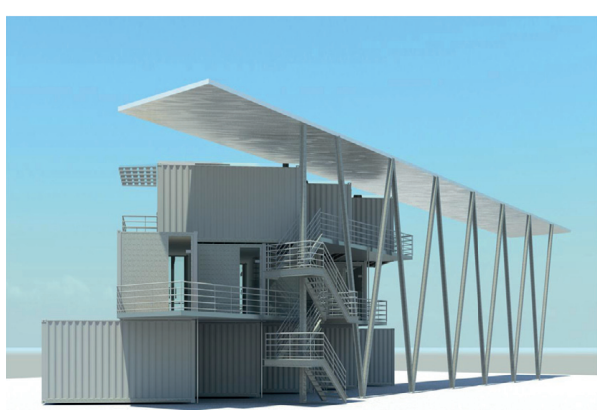

(b)

FiguRE 6: BIM model of modular steel structure buildings. (a) A single module. (b) Combination of modules, components, and parts of a modular steel structure building.

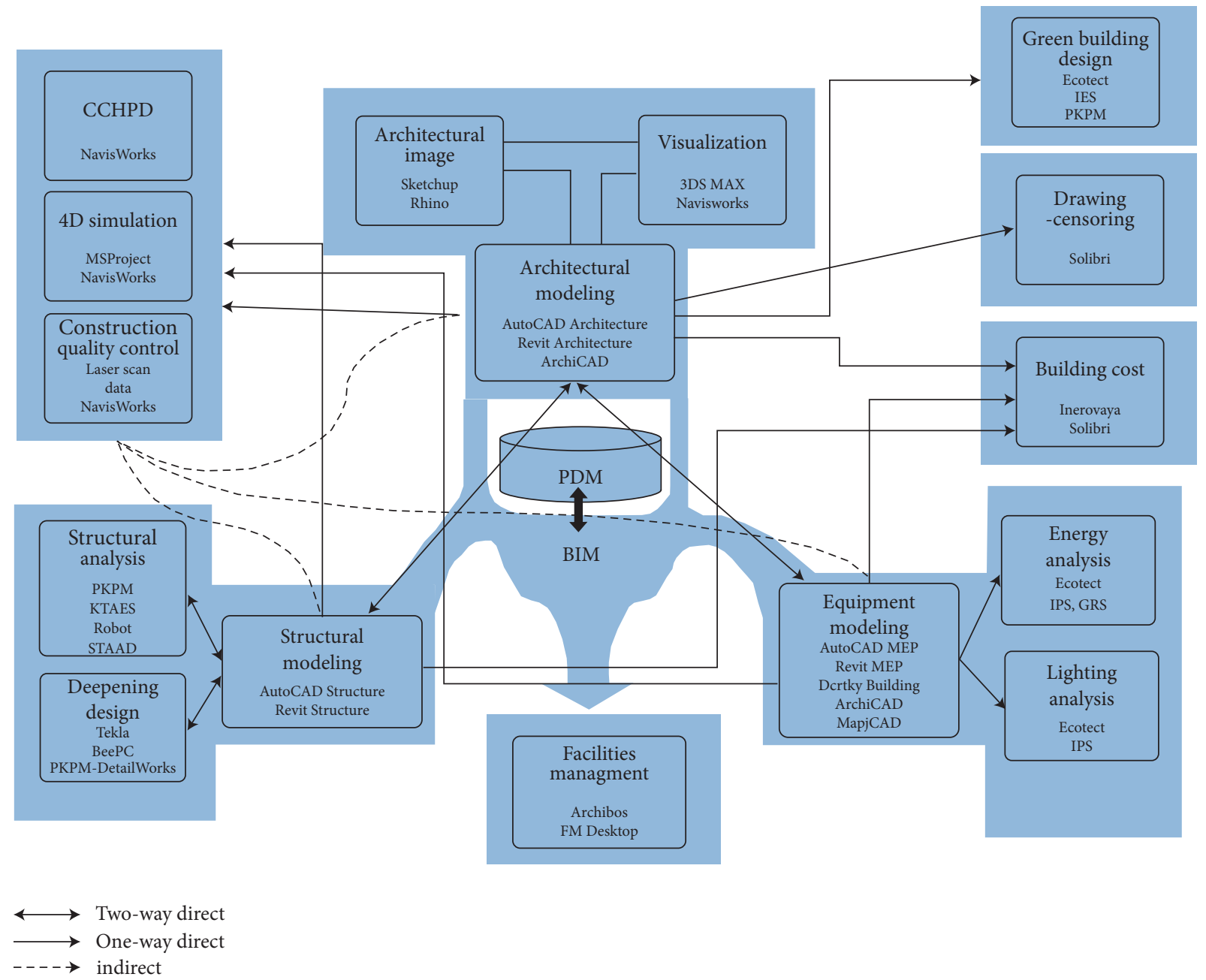

Figure 7: Analysis of greening of container buildings (Zhangzhou Shuangyu Island Hotel).

calculation results fail to meet the construction requirements, the relevant parameters of features and materials should be improved, until the calculation results meet the construction requirements. For example, in general, structural design software, the corrugated steel siding of the container module, cannot be used to establish the structural model directly. However, through analysis based on BIM platform with architectural structure software and mechanical structure software, it can be found that the corrugated steel walls can be combined with the upper and lower side beams, diagonal bracing (Figure 11(a)) can be used, and inner metal keel and the corrugated steel plate can be welded, to effectively strengthen the overall strength of the structure. Therefore, the Tourist Service Center successfully reduced the downward 

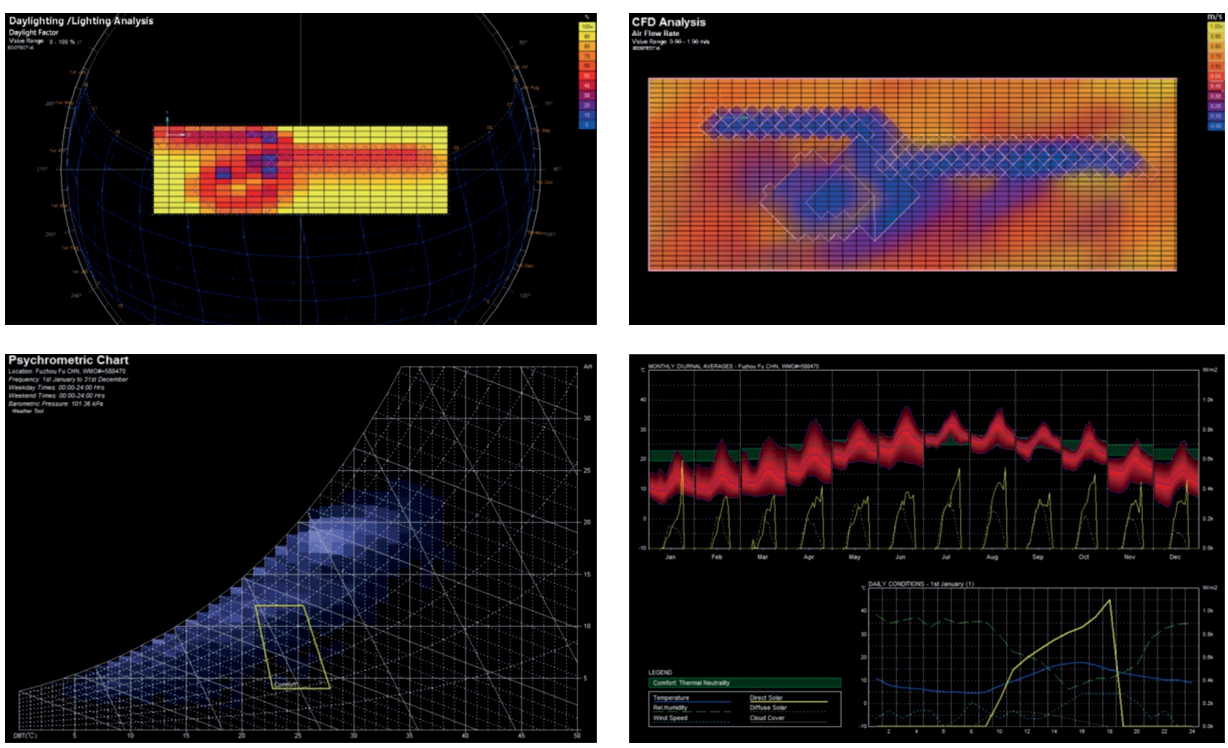

Figure 8: Photo of pilot projects. (a) Container modular fire station under construction. (b) Photo of "Xiangyu" Residence in Yangzhou Software Park. (c) Indoor photo of the container pilot project. (d) Photo of Yangzhou Suburb Park Maker Center.

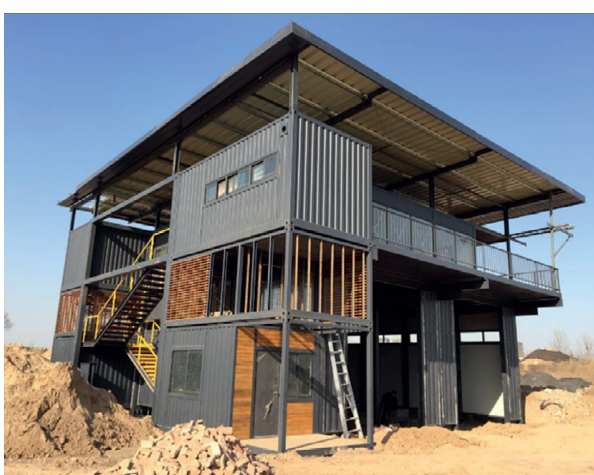

(a)
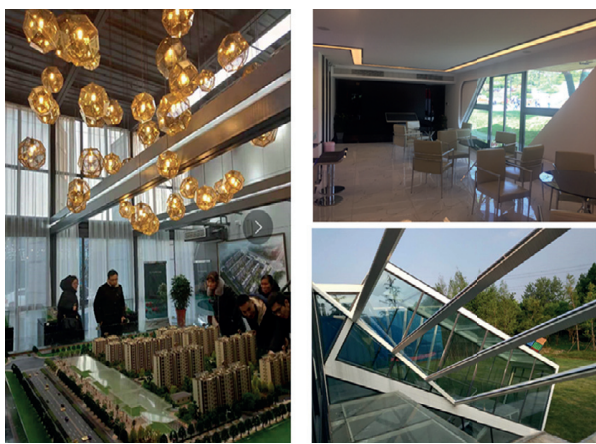

(c)

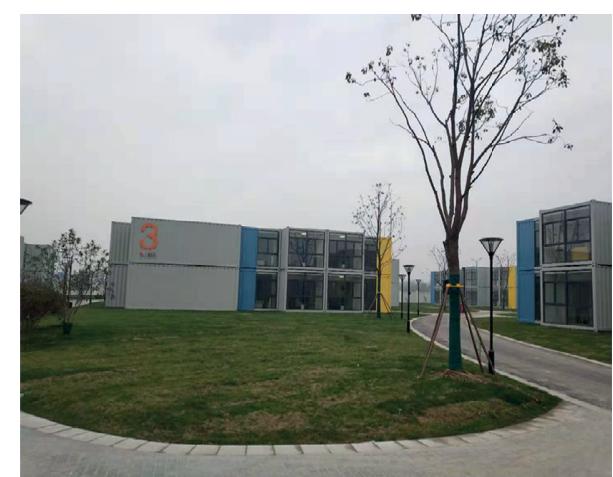

(b)

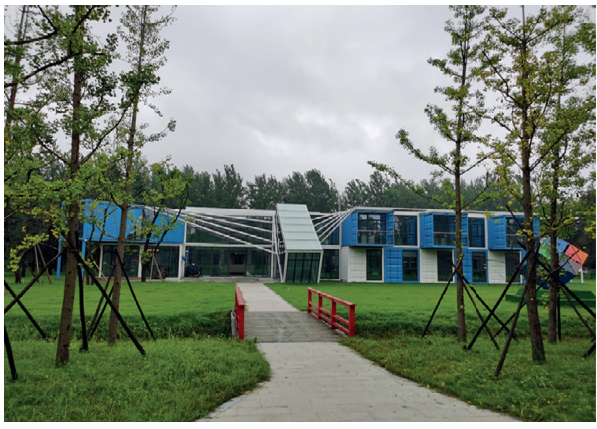

(d)

FIGURE 9: Finite element stress analysis on modules of a container building.

deflection of the cantilever structure and applied the architectural scheme of the large cantilever (maximum cantilever: 3.6 M) and ample space (Figure 11(b)) successfully passed the inspection upon completion. Due to the integration between BIM and PDM platforms, the adjustment of structural design and mechanical manufacturing information of the components can realize real-time two-way intercommunication; as thus, the component manufacturing drawing can be changed more efficiently, without mistakes; the parts can be conveniently classified, and their amount can be calculated, for facilitating the preparation of materials and fixtures by plants, thus promoting the factory production. As for the connection of nodes, the advanced module connection technology with independent intellectual property rights (patent number: 


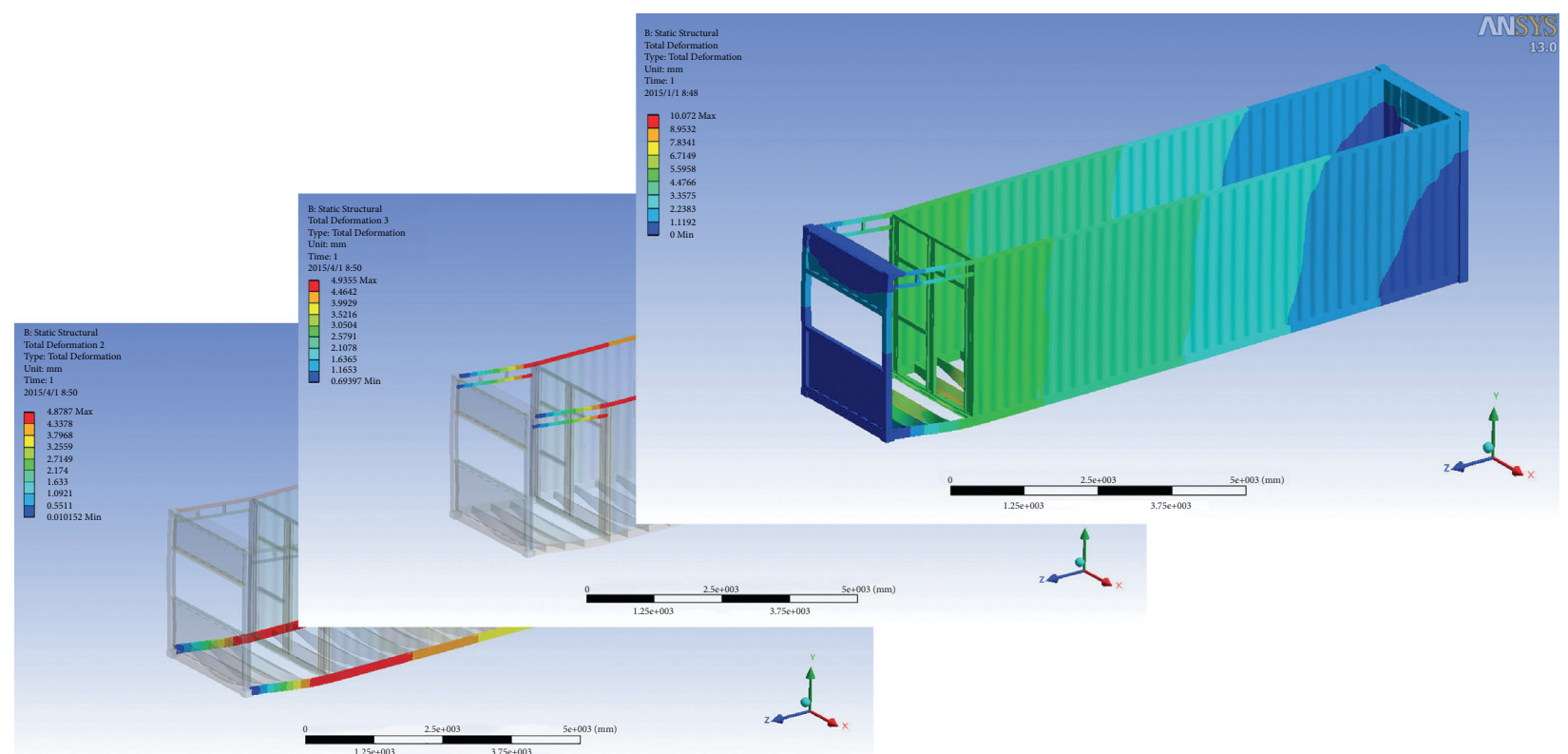

FIGURE 10: Integrated design information and software relationship based on BIM and PDM.

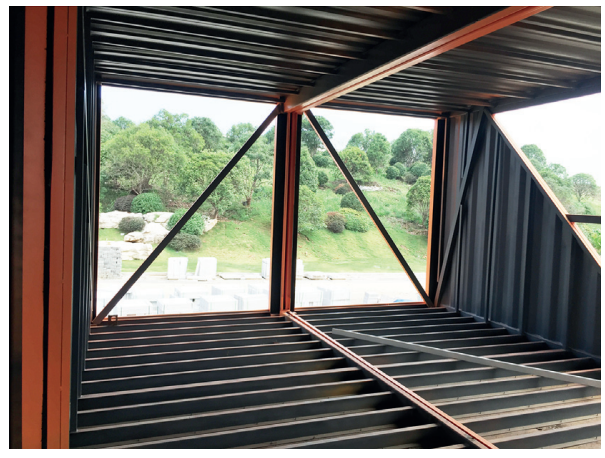

(a)

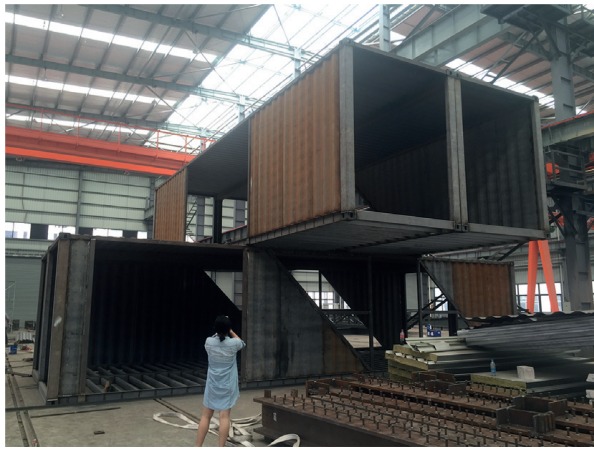

(b)

FIGURE 11: Photos of construction site. (a) Site installation of structurally strengthened modules. (b) Factory manufacturing and trial assembly of container building modules.
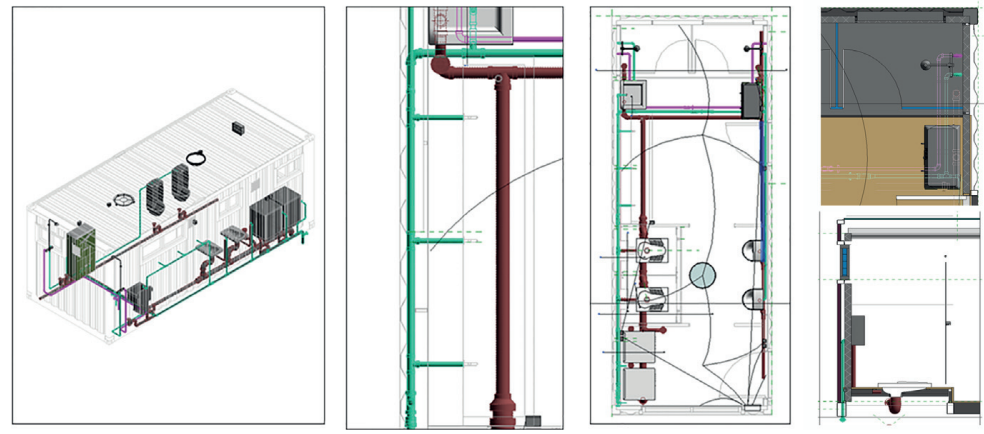

Figure 12: Comprehensive design of pipelines in bathroom based on BIM.

ZL2016 2 1236426.8) was adopted. The system consists of plug-in connectors, cover plates, and bolts. As proved by finite element analysis with Abaqus software and practice, it can provide sufficient rigidity and ensure structural integrity.
5.3. Comprehensive Design and Construction of Pipelines in Container Buildings Based on BIM. Prefabricated buildings have a high requirement for installation accuracy, and unlike traditional extensive wet construction methods, they have 
higher standards for integration of electromechanical pipelines from design and construction to application and maintenance. From factory production to site assembly, the pipeline interfaces of all building modules should be accurately connected, and no holes and grooves should be prepared to not damage the paint and steel plate. Based on the BIM model shared among various disciplines and the analysis function of software such as Revit, the conflicts in design can be easily found in the three-dimensional virtual environment, thus significantly improving the comprehensive design ability work efficiency of the pipelines. It can timely avoid errors and conflicts that may be encountered during the construction and significantly reduce the application for changes; in addition, it can also considerably increase the efficiency of construction, reduce the cost increase and construction delay due to coordination, and reduce the construction waste and damage to the buildings caused by rework. Taking the bathroom module with robust pipelines in the "Maker Center" Project as an example, the collision detection and visualization optimization design of the channels, sanitary ware, equipment, and steel structure, and interior decoration based on the BIM model reduced the occurrence of multiple collisions and avoided rework. In the 3D model, it was found that pipelines can be arranged in gaps between the trim panels and corrugated steel wall panels, which could optimize the integrated design of channels and interior decoration (Figure 12); this module specifically designed the connection interfaces of pipelines and gradually improved them as standardized interface components. For some more complicated constructions, software such as Autodesk Navisworks can be used to perform visual $4 \mathrm{D}$ construction simulation based on the BIM platform to optimize the construction scheme. The construction personnel can also perform construction disclosure with Fuzor and Autodesk Navisworks Manage and get familiar with the construction process and site conditions by construction preview to improve the efficiency of assembly and quality of completion.

\section{Conclusion}

In this study, the low design integration and the contradiction between standardization and diversity were found to be the bottlenecks restricting further development of the modular container building system. To fix this problem, it was proposed to establish a modulus system for modular container buildings and a database of components and parts of modular steel structure buildings, to strengthen professional coordination based on BIM and PDM platforms and improve the integrated design method for modular container buildings.

In this study, the related modules in the traditional construction industry and container manufacturing industry and the restrictions on dimensions in the logistics industry were coordinated based on BIM; and the unified container building modulus sequence and 3D modulus grid were proposed. A standardized and systematic database of components and parts characterized by "family" through the integration of BIM and PDM platforms and an integrated design method of container buildings led by architectural design based on the flexible modular combination and closely cooperated with structure and equipment, for realizing the standardization and digitization of the whole process of design, production, and construction were established.

The integrated design of modular steel structure container buildings based on BIM has been applied in several pilot projects, including Huaduhui Commercial Street and Modular Fire Station. As proved by practice, the application of this system has promoted the integration of the relevant standards in the two industries, strengthened the coordination of various disciplines, and improved the standardization, industrialization, and information levels of design, production, and construction. While adopting modules, prefabricated components, and components of the exact design specifications, the pilot projects also improved the buildings' spatial relevance and artistic quality. At present, the integrated design has made phased achievements. In the next step, the versatility of modules and components will be further studied, the composability of modules will be expanded, and the cost will be further reduced. In addition, as compared with the proposed integration target, the integration of this design system should be strengthened in the operation and maintenance phase and complete life cycle information management. In the future, incorporating the Internet of Things into the integrated design system will further promote the development of container buildings.

\section{Data Availability}

The data used to support the findings of this study are available from the corresponding author upon request.

\section{Conflicts of Interest}

The authors declare that there are no conflicts of interest regarding the publication of this study.

\section{Acknowledgments}

This study was supported by the Science and Technology Program of the Ministry of Housing and Urban-Rural Development (Grant no. 2016-K5-021).

\section{References}

[1] X. L. Gong and Y. K. Zhang, "Construction and modification of container-A sustainable development of construction trial," World Architecture, vol. 57, no. 10, pp. 124-125, 2010.

[2] P. C. H. Ling, C. S. Tan, Y. H. Lee, and Y. E. Tu, "Design consideration of container shelter in Malaysia," Jurnal Teknologi, vol. 83, no. 5, pp. 1-7, 2021.

[3] E. M. Grant, “"Pack 'em, rack 'em and stack 'em”: the appropriateness of the use and reuse of shipping containers for prison accommodation," Construction Economics And Building, vol. 13, no. 2, pp. 35-44, 2013.

[4] P. Zhao, Study on Adaptive Design and Construction of Container Buildings, Master's Degree Thesis, Hunan University, Changsha, China, 2011.

[5] L. L. Wong, "The new bud light steel system and the geometric shape evolution of light steel framework for COVID-19 
patients appointed hospital (Huoshenshan hospital)," Journal of Intelligent and Fuzzy Systems, vol. 39, pp. 9015-9026, 2020.

[6] C. Kriston, "Studio visit lot-ek," Architect, vol. 101, pp. 74-77, 2012.

[7] M. J. Hough and M. Lawson, "Design and construction of high-rise modular buildings based on recent projects," Proceedings of the Institution of Civil Engineers- Civil Engineering, vol. 172, no. 6, pp. 137-144, 2019.

[8] J. Alread, "Shigeru ban," Journal of Architectural Education, vol. 58, pp. 70-71, 2004

[9] A. Eissa, M. Monjur, and R. Yacine, "Factors for effective BIM governance," Journal of Building Engineering, vol. 10, pp. 89-101, 2017.

[10] M. K. Ansah, X. Chen, H. X. Yang, L. Lin, and L. Patrick, "Developing an automated BIM-based life cycle assessment approach for modularly designed high-rise buildings," Environmental Impact Assessment Review, vol. 90, Article ID 106618, 2021.

[11] Y. Lu, Q. Liu, Y. L. Chen, L. Yu, and S. S. Luo, "Research on structural design method of container house," Industrial Construction, vol. 44, no. 10, pp. 130-136+97, 2014.

[12] S. Qin, Z. C. Wu, and L. Yu, "Research on development of the interior system from KEP to KSI," Architectural Journal, vol. 61, no. 7, pp. 17-23, 2014.

[13] C. Zheng, Research on Integrated Architecture Design Based on BIM, Master's Degree Thesis, Central South University, Changsha, China, 2012.

[14] D. G. Guo, Computer Aided Architectural Design and Construction Management Based on BIM, Master's Degree Thesis, Xiamen University, Xiamen, China, 2014.

[15] M. Su and M. Gao, "A new exploration of prefabricated modular container buildings - design of Yangzhou Huaduhui Tourist Service Center," Jiangsu Construction, vol. 38, no. 4, pp. 27-30, 2018.

[16] S. Palos, A. Kiviniemi, and J. Kuusisto, "Future perspectives on product data management in building information Modeling," Construction Innovation, vol. 14, no. 1, pp. 52-68, 2014.

[17] S. Lemes and L. Lemes, "Blockchain in distributed cad environments," New Technologies, Development And Application II, vol. 76, pp. 25-32, 2020.

[18] M. Bertolini and L. Guardigli, "Upcycling shipping containers as building components: an environmental impact assessment," International Journal of Life Cycle Assessment, vol. 25, no. 6, pp. 947-963, 2020.

[19] M. Su and M. Gao, "Research on plant renovation and reuse based on container modular building," Industrial Construction, vol. 50, no. 1, pp. 75-79, 2020.

[20] K. Giriunas, H. Sezen, and R. B. Dupaix, "Evaluation, modeling, and analysis of shipping container building structures," Engineering Structures, vol. 43, pp. 48-57, 2012.

[21] J. Gu, "Structural design of modular container buildings," Building structure, vol. 51, no. S1, pp. 1152-1156, 2021.

[22] F. J. Luo, Y. Bai, J. Hou, and Y. Huang, "Progressive collapse analysis and structural robustness of steel-framed modular buildings," Engineering Failure Analysis, vol. 104, pp. 643656, 2019. 